\title{
Dynamic Interactive Cycles during the 2008 Financial Crisis
}

\author{
Ioannis M. Neokosmidis, Vassilis Polimenis \\ Department of Economics, Aristotle University of Thessaloniki, Thessaloniki, Greece \\ E-mail:ineokosm@econ.auth.gr,polymen@econ.auth.gr \\ Received February 16, 2010; revised March 20, 2010; accepted March 30, 2010
}

\begin{abstract}
This paper focuses on the analysis of the 2008 financial crisis and how it affects the global financial markets. We analyze three major markets (US, UK, and ASIA) that are represented by the levels of three broad stock indices S\&P 500, FTSE 100 and Hang Seng respectively. Our methodology is based on cointegration analysis and Granger causality test in order to examine the interaction between the markets (information flows). Additionally, we study the volatility transmission based on multivariate GARCH analysis. We find significant changes in information flows before and during the financial crisis.
\end{abstract}

Keywords: Unit Root Test, Cointegration, Granger Causality, Multivariate Volatility Processes, Financial Crisis

\section{Introduction}

Due to its surprising breadth and intensity, the analysis of the 2008 global financial crisis presents a major challenge for economists and financial experts. Policymakers now consider the definition of key policy responses and institutional rules in order to build mechanisms that will contain cross-market contagion and prevent a reoccurrence of the problem in the future. Most of the recent crises ${ }^{1}$ started from emerging markets, which are presumably more sensitive to liquidity shocks because of their underdeveloped and illiquid financial markets and their large public deficits. Besides the 1987 crash in Wall Street that was technical and short-lived in nature, the 2008 crisis is the first to be labelled a US crisis on the basis that it seems to have started by the massive US real estate delinquencies.

An important question related to an international financial crisis is the existence of contagion (i.e., the international propagation of country- or region-specific shocks to other parts of the world). According to the more open definition adopted by Forbes and Rigobon [1], contagion is measured as any change in the transmission mechanisms that occurs during a volatile period. For example, contagion may establish itself by a significant increase in cross-market correlations.

\footnotetext{
${ }^{1}$ The most well known financial and currency crises that have occurred over the last 25 years with global consequences were, the 1992 European monetary unit problems, the peso effect of 1994, and the 1997 Asian "flu" crisis (which also triggered the 1998 Russian "cold"). The 1999 Brazilian devaluation, the 2000 Internet bubble burst, and the July 2001 default of Argentina.
}

Yet to date, there is still a lot of disagreement as to what are the channels through which financial upheaval is transmitted across countries, and on the set of measurable factors that may be used for the precise identification of a contagion event. Understanding these factors is important because early recognition of the possibility of contagion may help reduce a country's vulnerability to externallyoriginated shocks.

In the wake of the current financial international crash, growing integration of financial markets has been of heightened interest because such integration is assumed to generate large, correlated price movements across most stock markets. Yet due to the complexity and global nature of the current financial crisis, it is difficult to move beyond the headlines of the financial press and provide an in depth analysis of the mechanism that links global financial markets during the crisis and generates the phenomenon of contagion.

The analysis may take place on both the economics of the crisis, as well as on a purely statistical manner. On the economic front, in the US for example, the fight has produced what is termed "a highly accommodative monetary policy." What is truly meant by this deceptively soft phrase is that since the onset of the financial crisis nearly two years ago, the Federal Reserve has reduced the cost of funds for big US banks nearly to zero. This has happened by adjusting the interest-rate target for overnight lending between banks (the so called Fed-funds rate).

Having brought the Fed-funds rate to almost zero, the US (and later the UK) switched to the more aggressive policy of Quantitative Easing, which is also described as 
"printing money out of thin air". This led to an explosion of the size of the US Fed balance sheet, mainly through the purchase of long-term securities, initially aimed at restarting the flow of credit and to soften the economic impact of the financial crisis for the US. Such actions were not paralleled elsewhere in Europe or Asia so it is interesting to understand the linkage dynamics that were produced.

In the current paper we employ an intuitive and straightforward statistical analysis for testing if contagion occurs by simply comparing cross-market linkages between markets during a relatively stable period before the turbulent period, with linkages during the crisis. We examine the short-run dynamics of returns and volatility for stocks traded in the US, British and Hong Kong stock exchanges during the relatively short last six year period. The main focus of the study is Granger causality among the three markets, which is a statistical concept of causality that is based on prediction. According to Granger causality, if a market "Granger-causes" (or "G-causes") another market, then past returns of the $1^{\text {st }}$ market should contain information that helps predict returns of the $2^{\text {nd }}$ above and beyond the information contained in past values of the $2^{\text {nd }}$ market alone.

We first find a strongly significant cointegration coefficient for the index levels before and during the financial crisis period for all market pairs (US-UK, US-Asia and UK-Asia), which implies a long run equilibrium level of interaction. We then proceed to the main finding of the paper: a change in the direction of the information flow during the financial crisis as this is established by Granger causality. As expected, due to overlapping operating hours and the strong ties between the markets, there is simultaneous interaction between the US and UK. Since the Asian markets precede the US with no overlap, Asian returns today ought to include an unrevealed component also present in yesterday's US returns. ${ }^{2}$ Yet, before the financial crisis, we can reject the hypothesis of the US market causing the Asian markets (at a daily level); this shows a particularly weak pre-crisis interaction. Surprisingly, when we test the null that US G-causes Asia with a sample which includes the financial crisis, we find that the US market includes information about Asia. This provides evidence of a newly produced channel of information from the US to Asia and, to our knowledge, the first statistical verification that the 2008 crisis was a crisis truly "...made in the US." The opening of this new channel of information flow from the US to Asia is a clear indication that during the financial crisis period the ability of the US markets to produce, capture and disseminate crisis specific information was unmatched by the financial markets in other regions of the world.

We finally move to understand the volatility transmission mechanism over time and across the three different

${ }^{2}$ This is also related to the non-synchronous trading theory of Lo and MacKinlay [2]. markets during the crisis. Our methodology is to examine the dynamic relationship between the daily stock market returns and their volatilities, for the three markets above, using a multivariate generalized autoregressive conditional heteroskedastic (GARCH) model. This is essentially a family of statistical models originally developed by Engle [3-5] and Bollerslev [6,7]. We find that the markets interact not only in a returns level but to some extend through volatility spillovers. The UK and Asian markets were insignificantly correlated before and during the crisis. For the US and Asian markets, changing information flows due to the crisis, manifested through Granger causality for US $\rightarrow$ Asia, is not corroborated by a change in the significance of the correlation coefficient. Finally, the US and UK are the only significantly correlated markets.

\section{Data Analysis and Descriptive Statistics}

The dataset used includes the closing levels of the daily stock market indices for three major stock markets (US, UK and Hong Kong). We use the S\&P 500 index for the US, the FTSE100 for the UK and the Hang Seng index as a proxy for the Asian markets. Furthermore, we examine the econometrics of these series in two data samples. The first sample, with data not contaminated with the crisis, runs from April 2002 to April 2006; i.e., ends before the onset of the financial crisis. The second sample, from April 2002 to April 2009, includes at least the first 18 to 20 months of the crisis depending on when one places its beginning. We compute the daily stock returns for each index as the first difference of logarithmic levels. Tables 1(a) and (b) report return summary statistics for the two time intervals. Table 1(a) includes the time space before the financial crisis (FC from now on) and Table 1(b) presents the results of summary statistics including the period of FC (2nd semester 2007-April 2009).

As we can see from Table 1(a), Asia gives the highest mean return while it is characterized by lower volatility with positive skewness and no excess kurtosis in compare with US and UK. US gives the second higher mean return with the second lower volatility. Additionally, it is skewed to the right with no excess kurtosis. The most risky market is the UK market in the time interval before the FC, while it seems to give the lower mean returns with negative skewness and excess kurtosis.

We get the results as they are shown in Table 1(b), including the time period of FC in our analysis. The FC gives the opposite side of the coin while ASIA, as it is represented by the Hang Seng index, is shown to be the most aggressive market in comparison with the US and UK. Asia gives the highest mean returns with the highest standard deviation, while it remained skewed to the right. US and UK both exhibit negative average returns when the FC period is included in the sample. Finally, all three markets exhibit excess kurtosis. 
Table 1. Return summary statistics for the representative time series.

(a) Summary statistics for index returns before FC.

\begin{tabular}{lccc}
\hline & ASIA & US & UK \\
\hline Mean & 0.000429 & 0.000155 & 0.000146 \\
Standard Deviation & 0.009964 & 0.010637 & 0.011334 \\
Skewness & 0.029616 & 0.280395 & -0.1527 \\
Kurtosis & 1.236111 & 2.998876 & 4.878168 \\
Minimum & -0.04184 & -0.04242 & -0.05589 \\
Maximum & 0.04051 & 0.055744 & 0.059038 \\
\hline
\end{tabular}

(b) Summary statistics for index returns during FC.

\begin{tabular}{lccc}
\hline & ASIA & US & UK \\
\hline Mean & 0.000217 & -0.000146 & -0.00015 \\
Standard Deviation & 0.016746 & 0.014337 & 0.013954 \\
Skewness & 0.093149 & -0.10694 & -0.09052 \\
Kurtosis & 10.683329 & 9.533261 & 7.320857 \\
Minimum & -0.13582 & -0.10694 & -0.09265 \\
Maximum & 0.134068 & 0.109572 & 0.093842 \\
\hline
\end{tabular}

\section{Methodology}

It is well known that testing for cointegration is a means for correctly testing hypotheses concerning the relationship between two indices that have unit roots. In an effort to firstly determine if the time series is covariance stationary we employ the Augmented Dickey-Fuller test $[8,9]$ for a unit root. We will then test for cointegration.

Firstly, we employ a unit root test in order to check for nonstationarity between our time series. We then test for a significant cointegration coefficient between each market pairs. Moreover, we test for Granger causality in each pair of the series in order to investigate the interaction flows among the markets before and during the financial crisis time horizon. Finally we apply a DVEC (1, 1) model and a CCC model in order to capture the volatility transmission by examining the changes in the correlation and covariance coefficients.

\subsection{Testing for Unit Roots}

We have to determine the order of integration of stock price series before we test for cointegration. For this propose, we consider an Augmented Dickey-Fuller (ADF) test for each of our time series. So, the test procedure is described by the following equations about the US, UK and Asian markets:

$$
\Delta U S_{t}=\xi_{1}+a_{1} t+(p-1) U S_{t-1}+\sum_{i=1}^{k} \theta_{1, i} \Delta U S_{t-i}+u_{1, t}
$$

$$
\begin{aligned}
& \Delta U K_{t}=\xi_{2}+a_{2} t+(p-1) U K_{t-1}+\sum_{i=1}^{k} \theta_{2, i} \Delta U K_{t-i}+u_{2, t} \\
& \Delta H S_{t}=\xi_{3}+a_{3} t+(p-1) H S_{t-1}+\sum_{i=1}^{k} \theta_{3, i} \Delta H S_{t-i}+u_{3, t}
\end{aligned}
$$

with $U S_{t}$ representing the log level of the S\&P 500 index at time $t, U K_{t}$ representing the log FTSE100 and the log level of the Hang Seng composite index being measured in $H S_{t}{ }^{3}$. It is assumed that $u_{i, t} \sim \operatorname{iid}\left(o, \sigma_{u_{i}}^{2}\right)$, in all system equations.

Finally, it is important to notice that, for the fitted error terms $\left(\hat{u}_{t}\right)$ to be as close as possible to white noise, we have to select the correct number of lags based on an information criterion such as the AIC [10].

The null hypothesis for the ADF test is that series are integrated

$$
H_{0}:(p-1)=0
$$

against the alternative hypothesis of no integration,

$$
H_{1}:(p-1) \prec 0
$$

t-tests in order to accept or reject the null hypothesis of a unit root are performed against critical values from the DF-distribution [11] and not from the classical t-distribution.

Tables 2(a) and (b) show the test results; the null hypothesis of nonstationarity cannot be rejected for all the markets and for both time horizons. So, all time series $\left(U S_{t}\right.$, $\left.U K_{t}, H S_{t}\right)$ can be assumed to be $\mathrm{I}(1)$ which means that we should take the first difference (i.e., continuously compounded index returns) in order to achieve stationarity.

\subsection{Testing for Cointegration}

We concluded on integrated of order one I(1) level series in the previous section. In this section, we test for cointegration on each pair of processes in order to determine the existence of long-run equilibria. A significant cointegration coefficient implies a long-run equilibrium relationship. Then, even though our data generating processes contain unit root, they are going to move closely together with the difference between them will be stationary [11]. We employ the Engle and Granger test procedure [12] in order to test for cointegration:

1st step: We have to test if our series are I(1).

2nd step: We run the regressions between $\left(U S_{t} / U K_{t}\right.$, $U S_{t} / H S_{t}, U K_{t} / H S_{t}$ ) in both periods (before and after FC). Our regression models are:

$$
\begin{aligned}
& U S_{t}=a_{0}+a_{1} U K_{t}+u_{t} \\
& U S_{t}=a_{0}+a_{1} H S_{t}+u_{t}
\end{aligned}
$$

\footnotetext{
${ }^{3}$ Clearly then, $\Delta U S_{t}, \Delta U K_{t}$ and $\Delta H S_{t}$ are the daily returns of the US, UK
} and HS indices. 
Table 2(a). Unit root-10 ${ }^{\text {th }}$ lag-test for S\&P 500, FTSE 100 and Hang Seng time series before FC time period.

Unit root test for S\&P 500 time series before the FC time horizon.

\begin{tabular}{ccccccccc}
\hline D-lag & t-adf & beta Y_1 & sigma & t-DY_lag & t-prob & AIC & F-prob \\
\hline 10 & -0.8879 & 0.99484 & 0.01063 & -1.512 & 0.1308 & -9.075 & \\
9 & -1.064 & 0.99385 & 0.01064 & 0.3090 & 0.7574 & -9.074 & 0.1308 \\
8 & -1.036 & 0.99405 & 0.01063 & 2.053 & 0.0403 & -9.076 & 0.3042 \\
7 & -0.7980 & 0.99544 & 0.01065 & -2.672 & 0.0077 & -9.074 & 0.0865 \\
6 & -1.123 & 0.99361 & 0.01068 & -0.4034 & 0.6867 & -9.069 & 0.0084 \\
5 & -1.181 & 0.99333 & 0.01068 & -0.4170 & 0.6767 & -9.071 & 0.0166 \\
4 & -1.243 & 0.99304 & 0.01068 & -0.8420 & 0.4000 & -9.073 & 0.0293 \\
3 & -1.364 & 0.99243 & 0.01067 & -0.1313 & 0.8956 & -9.074 & 0.0394 \\
2 & -1.392 & 0.99234 & 0.01067 & 0.1366 & 0.8913 & -9.076 & 0.0638 \\
1 & -1.387 & 0.99244 & 0.01066 & -1.423 & 0.1551 & -9.078 & 0.0967 \\
0 & -1.583 & 0.99144 & 0.01067 & & & -9.078 & 0.078 \\
\hline
\end{tabular}

Notes: S\&P 500 represents the US financial stock market and the test time interval is considered to be from April 2002 to April 2006 . The above results were based on PcGive output where the selection criteria are obviously shown.

Unit root test for FTSE100 time series before the FC time horizon.

\begin{tabular}{cccccccc}
\hline D-lag & t-adf & beta Y_1 & sigma & t-DY_lag & t-prob & AIC & F-prob \\
\hline 10 & 0.1882 & 1.0009 & 0.01110 & -3.758 & 0.0002 & -8.989 & \\
9 & -0.2984 & 0.99853 & 0.01117 & 1.715 & 0.0867 & -8.977 & 0.0002 \\
8 & -0.08379 & 0.99959 & 0.01118 & 2.053 & 0.0404 & -8.976 & 0.0002 \\
7 & 0.1637 & 1.0008 & 0.01120 & 0.4584 & 0.6468 & -8.974 & 0.0001 \\
6 & 0.2209 & 1.0011 & 0.01120 & -2.310 & 0.0211 & -8.975 & 0.0003 \\
5 & -0.05607 & 0.99973 & 0.01122 & -1.281 & 0.2004 & -8.972 & 0.0001 \\
4 & -0.2088 & 0.99901 & 0.01122 & 1.259 & 0.2082 & -8.972 & 0.0001 \\
3 & -0.05834 & 0.99972 & 0.01123 & -4.637 & 0.0000 & -8.973 & 0.0001 \\
2 & -0.6220 & 0.99705 & 0.01134 & 0.9654 & 0.3346 & -8.953 & 0.0000 \\
1 & -0.5116 & 0.99759 & 0.01134 & -2.555 & 0.0108 & -8.954 & 0.0000 \\
0 & -0.8261 & 0.99613 & 0.01137 & & & -8.950 & 0.0000 \\
\hline
\end{tabular}

Notes: FTSE 100 represents the UK financial stock market and the test time interval is considered to be from April 2002 to April 2006. The above results were based on PcGive output where the selection criteria are obviously shown.

Unit root test for Hang Seng time series before the FC time horizon.

\begin{tabular}{ccccccccc}
\hline D-lag & t-adf & beta Y_1 & sigma & t-DY_lag & t-prob & AIC & F-prob \\
\hline 10 & -1.510 & 0.99393 & 0.009941 & 0.8272 & 0.4083 & -9.209 & \\
9 & -1.443 & 0.99422 & 0.009939 & -1.961 & 0.0501 & -9.210 & 0.4083 \\
8 & -1.625 & 0.99351 & 0.009953 & -1.271 & 0.2041 & -9.209 & 0.1044 \\
7 & -1.750 & 0.99303 & 0.009957 & 1.368 & 0.1716 & -9.209 & 0.1053 \\
6 & -1.632 & 0.99353 & 0.009961 & 1.608 & 0.1081 & -9.209 & 0.0915 \\
5 & -1.497 & 0.99408 & 0.009969 & -0.0759 & 0.9395 & -9.208 & 0.0603 \\
4 & -1.510 & 0.99405 & 0.009964 & -1.603 & 0.1092 & -9.210 & 0.1018 \\
3 & -1.654 & 0.99350 & 0.009972 & 0.4320 & 0.6658 & -9.210 & 0.0684 \\
2 & -1.624 & 0.99365 & 0.009968 & 0.3827 & 0.7021 & -9.212 & 0.1004 \\
1 & -1.599 & 0.99377 & 0.009964 & 1.429 & 0.1533 & -9.214 & 0.1412 \\
0 & -1.494 & 0.99419 & 0.009969 & & & -9.214 & 0.1136 \\
\hline
\end{tabular}

Notes: Hang Seng represents the ASIA financial stock market and the test time interval is considered to be from April 2002 to April 2006 . The above results were based on PcGive output where the selection criteria are obviously shown. 
Table 2(b). Unit root-10 ${ }^{\text {th }}$ lag-test for S\&P 500, FTSE 100 and Hang Seng time series including the FC time period.

Unit root test for FTSE 100 time series during FC time horizon.

\begin{tabular}{cccccccc}
\hline D-lag & t-adf & beta Y_1 & sigma & t-DY_lag & t-prob & AIC & F-prob \\
\hline 10 & -2.918 & 0.99329 & 0.01358 & -0.2116 & 0.8324 & -8.591 & \\
9 & -2.923 & 0.99328 & 0.01357 & -0.05951 & 0.9525 & -8.593 & 0.8324 \\
8 & -2.926 & 0.99328 & 0.01357 & 2.242 & 0.0251 & -8.594 & 0.9761 \\
7 & -2.885 & 0.99337 & 0.01358 & 1.853 & 0.0640 & -8.592 & 0.1673 \\
6 & -2.862 & 0.99342 & 0.01359 & -3.136 & 0.0017 & -8.591 & 0.0751 \\
5 & -2.909 & 0.99329 & 0.01363 & -2.906 & 0.0037 & -8.587 & 0.0026 \\
4 & -2.973 & 0.99313 & 0.01366 & 4.460 & 0.0000 & -8.583 & 0.0002 \\
3 & -2.875 & 0.99332 & 0.01373 & -4.666 & 0.0000 & -8.573 & 0.0000 \\
2 & -2.990 & 0.99302 & 0.01381 & -1.729 & 0.0840 & -8.562 & 0.0000 \\
1 & -3.034 & 0.99292 & 0.01382 & -3.489 & 0.0005 & -8.561 & 0.0000 \\
0 & -3.131 & 0.99267 & 0.01386 & & & -8.555 & 0.0000 \\
\hline
\end{tabular}

Notes: FTSE 100 represents the UK financial stock market and the test time interval is considered to be from April 2002 to April 2009. The above results were based on PcGive output where the selection criteria are obviously shown.

Unit root test for S\&P 500 time series during FC time horizon.

\begin{tabular}{cccccccc}
\hline D-lag & t-adf & beta Y_1 & sigma & t-DY_lag & t-prob & AIC & F-prob \\
\hline 10 & -3.250 & 0.99305 & 0.01404 & 1.671 & 0.0949 & -8.524 & \\
9 & -3.241 & 0.99306 & 0.01405 & -0.3647 & 0.7154 & -8.523 & 0.0949 \\
8 & -3.244 & 0.99306 & 0.01405 & 1.943 & 0.0521 & -8.524 & 0.2320 \\
7 & -3.235 & 0.99307 & 0.01406 & -2.093 & 0.0365 & -8.523 & 0.0824 \\
6 & -3.244 & 0.99305 & 0.01407 & 0.1643 & 0.8695 & -8.522 & 0.0258 \\
5 & -3.245 & 0.99305 & 0.01407 & -1.265 & 0.2059 & -8.523 & 0.0495 \\
4 & -3.246 & 0.99304 & 0.01407 & -1.576 & 0.1152 & -8.523 & 0.0481 \\
3 & -3.258 & 0.99301 & 0.01408 & 2.592 & 0.0096 & -8.523 & 0.0338 \\
2 & -3.242 & 0.99304 & 0.01410 & -4.334 & 0.0000 & -8.520 & 0.0052 \\
1 & -3.269 & 0.99294 & 0.01417 & -4.721 & 0.0000 & -8.511 & 0.0000 \\
0 & -3.320 & 0.99279 & 0.01426 & & & -8.499 & 0.0000 \\
\hline
\end{tabular}

Notes: S\&P 500 represents the US financial stock market and the test time interval is considered to be from April 2002 to April 2009. The above results were based on PcGive output where the selection criteria are obviously shown.

Unit root test for Hang Seng time series during FC time horizon.

\begin{tabular}{cccccccc}
\hline D-lag & t-adf & beta Y_1 & sigma & t-DY_lag & t-prob & AIC & F-prob \\
\hline 10 & -2.803 & 0.99388 & 0.01650 & -2.851 & 0.0044 & -8.201 & \\
9 & -2.877 & 0.99370 & 0.01654 & -2.119 & 0.0343 & -8.198 & 0.0044 \\
8 & -2.942 & 0.99356 & 0.01655 & 1.683 & 0.0926 & -8.196 & 0.0018 \\
7 & -2.900 & 0.99365 & 0.01656 & 0.615 & 0.5387 & -8.196 & 0.0015 \\
6 & -2.887 & 0.99368 & 0.01656 & 1.319 & 0.1872 & -8.197 & 0.0033 \\
5 & -2.863 & 0.99373 & 0.01656 & -1.711 & 0.0872 & -8.197 & 0.0036 \\
4 & -2.902 & 0.99364 & 0.01657 & -0.897 & 0.3696 & -8.196 & 0.0023 \\
3 & -2.926 & 0.99359 & 0.01657 & -1.913 & 0.0559 & -8.197 & 0.0034 \\
2 & -2.974 & 0.99349 & 0.01658 & 0.3531 & 0.7240 & -8.196 & 0.0016 \\
1 & -2.967 & 0.99351 & 0.01658 & -1.531 & 0.1259 & -8.197 & 0.0029 \\
0 & -2.996 & 0.99344 & 0.01659 & & & -8.197 & 0.0022 \\
\hline
\end{tabular}

Notes: Hang Seng represents the ASIA financial stock market and the test time interval is considered to be from April 2002 to April 2009. The above results were based on PcGive output where the selection criteria are obviously shown. 


$$
U K_{t}=a_{0}+a_{1} H S_{t}+u_{t}
$$

3rd step: We obtain the fitted errors $\left(\hat{u}_{t}\right)$ from the above regressions and we test if they include any stochastic trends or not. Then, if we find unit roots in the residuals we conclude that there is no cointegration between the series. So, we apply an ADF test in the fitted errors,

$$
\Delta \hat{u}_{t}=a \hat{u}_{t-1}+\sum_{i=1}^{k} b_{i} \Delta \hat{u}_{t-i}+\varepsilon_{t}
$$

where the null is:

$$
H_{0}: a=0
$$

against the alternative,

$$
H_{1}: a \prec 0
$$

The results are shown in Tables 3 and 4, where we reject the null (no cointegration) at all lags for all market pairs. The financial crisis does not affect the existence of long-run relationship among the three markets.

\subsection{Information Flow}

Even if the financial crisis did not affect the long-run relationship of the markets, it may still have affected the flow of information (the direction of interaction) between them. As we discussed already, we find cointegration between (US/UK), (US/HS) and (UK/HS) markets. Yet, we don't know the direction of information flow (direction of interaction) between the markets.

As is well known Granger causality from $X$ to $Y$ does not indicate causality in the proper common use of the term (i.e., it does not imply that the $Y$ series is the effect or the result of $X$ series). Instead, Granger causality truly measures precedence and information flow, so that in our context here of the recent financial crisis Granger causality from a country $X$ to country $Y$ implies that information during the crisis flows from $X$ to $Y$. Alternatively, we may think of developments in $X$ preceding developments in $Y$.

Our aim in this section is to describe the dynamic interaction between the markets and to see the independent movements before we proceed to volatility modelling. It is a crucial aspect of a proper analysis of the crisis to analyze the cycle of information before we move to the next level of volatility analysis.

We separate our markets in three bi-variate VAR processes [13] like following:

$$
\begin{aligned}
& \left\{\begin{array}{l}
\Delta U S_{t}=\xi_{1}+c_{1,1} \Delta U S_{t-1}+c_{1,2} \Delta U K_{t-1}+v_{1 t} \\
\Delta U K_{t}=\xi_{2}+c_{2,1} \Delta U S_{t-1}+c_{2,2} \Delta U K_{t-1}+v_{2 t}
\end{array}\right\} \\
& \left\{\begin{array}{l}
\Delta U S_{t}=\xi_{1}+c_{1,1} \Delta U S_{t-1}+c_{1,2} \Delta H S_{t-1}+\eta_{1 t} \\
\Delta H S_{t}=\xi_{2}+c_{2,1} \Delta U S_{t-1}+c_{2,2} \Delta H S_{t-1}+\eta_{2 t}
\end{array}\right\}
\end{aligned}
$$

$$
\left\{\begin{array}{l}
\Delta U K_{t}=\xi_{1}+c_{1,1} \Delta U K_{t-1}+c_{1,2} \Delta H S_{t-1}+\varepsilon_{1 t} \\
\Delta H S_{t}=\xi_{2}+c_{2,1} \Delta U K_{t-1}+c_{2,2} \Delta H S_{t-1}+\varepsilon_{2 t}
\end{array}\right\}
$$

Alternatively, in the absence of Granger causality, our series are generated by an AR(1) process as follows:

$$
\begin{aligned}
& \Delta U S_{t}=a_{1}+p_{1} \Delta U S_{t-1}+u_{1 t} \\
& \Delta H S_{t}=a_{2}+p_{2} \Delta H S_{t-1}+u_{2 t} \\
& \Delta U K_{t}=a_{3}+p_{3} \Delta U K_{t-1}+u_{3 t}
\end{aligned}
$$

We say that $\left(R_{i, t}\right)$ return series does not Granger cause ( $G$-cause) the $\left(R_{j, t}\right)$ return series if and only if the best linear prediction of $R_{j, t}$ given the information set $\left\{R_{i, t-1}\right.$, $R_{j, t-1}$ ) does not depend on $R_{i, t-1 \text {. }}$

Following the above modelling, we can test the null hypothesis against the alternative:

UK does not G-cause US:

$$
\begin{aligned}
& H_{0}: c_{1,2}=0 \\
& H_{1}: c_{1,2} \neq 0
\end{aligned}
$$

or alternatively, we may say that under the null hypothesis the residual variances in (5) and (8) above are the same since $\Delta U K_{t-1}$ does not have any significance in explaining $\Delta U S_{t}$, i.e.

$$
\begin{aligned}
& H_{0}: E\left(v_{1 t}^{2}\right)=E\left(u_{1 t}^{2}\right) \\
& H_{1}: E\left(v_{1 t}^{2}\right) \neq E\left(u_{1 t}^{2}\right)
\end{aligned}
$$

US does not G-cause UK:

$$
\begin{array}{lll}
H_{0}: c_{2,1}=0 & \text { or } & H_{0}: E\left(v_{2 t}^{2}\right)=E\left(u_{3 t}^{2}\right) \\
H_{1}: c_{2,1} \neq 0 & & H_{1}: E\left(v_{2 t}^{2}\right) \neq E\left(u_{3 t}^{2}\right)
\end{array}
$$

HS does not G-cause US:

$$
\begin{array}{lll}
H_{0}: c_{1,2}=0 & \text { or } & H_{0}: E\left(\eta_{1 t}^{2}\right)=E\left(u_{1 t}^{2}\right) \\
H_{1}: c_{1,2} \neq 0 & & H_{1}: E\left(\eta_{1 t}^{2}\right) \neq E\left(u_{1 t}^{2}\right)
\end{array}
$$

US does not G-cause HS:

$$
\begin{aligned}
& H_{0}: c_{2,1}=0 \\
& H_{1}: c_{2,1} \neq 0
\end{aligned} \text { or } \begin{aligned}
& H_{0}: E\left(\eta_{2 t}^{2}\right)=E\left(u_{2 t}^{2}\right) \\
& H_{1}: E\left(\eta_{2 t}^{2}\right) \neq E\left(u_{2 t}^{2}\right)
\end{aligned}
$$

\section{HS does not G-cause UK:}

$$
\begin{array}{lll}
H_{0}: c_{1,2}=0 & \text { or } & H_{0}: E\left(\varepsilon_{1 t}^{2}\right)=E\left(u_{3 t}^{2}\right) \\
H_{1}: c_{1,2} \neq 0 & & H_{1}: E\left(\varepsilon_{1 t}^{2}\right) \neq E\left(u_{3 t}^{2}\right)
\end{array}
$$

UK does not G-cause HS:

$$
\begin{array}{lll}
H_{0}: c_{2,1}=0 & \text { or } & H_{0}: E\left(\varepsilon_{2 t}^{2}\right)=E\left(u_{2 t}^{2}\right) \\
H_{1}: c_{2,1} \neq 0 & & H_{1}: E\left(\varepsilon_{2 t}^{2}\right) \neq E\left(u_{2 t}^{2}\right)
\end{array}
$$

\subsubsection{Estimation and Testing}

We have already described an assumed regression structure for our series. We perform maximum likelihood 
Table 3. Regression results for the (US/UK), (US/HS) and (UK/HS) markets before and during FC horizon.

Regression results between US and UK markets before FC time duration.

\begin{tabular}{cccccc}
\hline & Coefficient & Std.Error & t-value & t-prob & Part.R $^{2}$ \\
\hline$a_{0}$ & -0.608626 & 0.1167 & -5.21 & 0.000 & 0.0263 \\
$a_{1}$ & 0.900251 & 0.01384 & 65.0 & 0.000 & 0.8077
\end{tabular}

RSS: (3.15426053), $\left(\mathrm{R}^{2}\right): 0.807715$

$\mathrm{F}(1,1007)=4230[0.000]^{* *}$

Log-likelihood (1478.23); DW: (0.0662)

Notes: The regression equation is $\left(U S_{t}=a_{0}+a_{1} U K_{t}+u_{t}\right) . U S_{t}$ is represented by S\&P 500 index data, and $U K_{t}$ is represented by FTSE 100 index data. Both samples of data are referred to time interval from April 2002 to April 2006.

Regression results between UK and ASIA markets before FC time duration.

\begin{tabular}{cccccc}
\hline & Coefficient & Std.Error & t-value & t-prob & Part.R ${ }^{2}$ \\
\hline$a_{0}$ & 2.32598 & 0.09418 & 24.7 & 0.000 & 0.3805 \\
$a_{1}$ & 0.648937 & 0.01001 & 64.8 & 0.000 & 0.8088
\end{tabular}

RSS: (3.08452898), $\left(\mathrm{R}^{2}\right): 0.808844$

$\mathrm{F}(1,993)=4202[0.000]^{* *}$

Log-likelihood: (1461.89); DW: (0.0579)

Notes: The regression equation is $\left(U K_{t}=a_{0}+a_{1} H S_{t}+u_{t}\right)$. $U K_{t}$ is represented by FTSE 100 index data, and $H S_{t}$ is represented by Hang Seng index data. Both samples of data are referred to time interval from April 2002 to April 2006.

Regression results between US and ASIA markets before FC time duration.

\begin{tabular}{cccccc}
\hline & Coefficient & Std.Error & t-value & t-prob & Part.R ${ }^{2}$ \\
\hline$a_{0}$ & 0.535682 & 0.07269 & 7.37 & 0.000 & 0.0519 \\
$a_{1}$ & 0.685310 & 0.007727 & 88.7 & 0.000 & 0.8879
\end{tabular}

RSS: (1.8376384), $\left(\mathrm{R}^{2}\right): 0.887904$

$\mathrm{F}(1,993)=7865[0.000]^{* *}$

Log-likelihood (1719.55); DW: (0.0842)

Notes: The regression equation is $\left(U S_{t}=a_{0}+a_{1} H S_{t}+u_{t}\right) . U S_{t}$ is represented by S\&P 500 index data, and $H S_{t}$ is represented by Hang Seng index data. Both samples of data are referred to time interval from April 2002 to April 2006.

estimation (MLE), with MLE estimators actually identical to OLS estimators.

The log-likelihood function for our models, assuming the $\operatorname{iidN}\left(o, \sigma^{2}\right)$ for the residuals, is of the following form

$$
\begin{aligned}
& \log L=-(T / 2) \log (2 \pi)-(T / 2) \log \left(\sigma_{j \rightarrow i}^{2}\right) \\
& -\left(1 / 2 \sigma_{j \rightarrow i}^{2}\right) \sum_{t=1}^{T}\left(y_{i, t}-\xi_{i}-a_{i} y_{i, t-1}-b_{i} y_{j, t-1}\right)^{2} \\
& \forall i \neq j=1,2,3
\end{aligned}
$$

where $\left(y_{1, t}=\Delta U S_{t}, y_{2, t}=\Delta H S_{t}, y_{3, t}=\Delta U K_{t}\right)$ and $\sigma_{j \rightarrow i}^{2}$
Regression results between US and ASIA markets into FC time duration.

\begin{tabular}{cccccc}
\hline & Coefficient & Std.Error & t-value & t-prob & Part.R $^{2}$ \\
\hline$a_{0}$ & 2.35806 & 0.07410 & 31.8 & 0.000 & 0.3671 \\
$a_{1}$ & 0.488369 & 0.007705 & 63.4 & 0.000 & 0.6971
\end{tabular}

RSS: (17.4253079), $\left(\mathrm{R}^{2}\right): 0.697063$

$\mathrm{F}(1,1746)=4018[0.000]^{* *}$

Log-likelihood: (1547.35); DW: (0.0235)

Notes: The regression equation is $\left(U S_{t}=a_{0}+a_{1} H S_{t}+u_{t}\right) . U S_{t}$ is represented by S\&P 500 index data, and $H S_{t}$ is represented by Hang Seng index data. Both samples of data are referred to time interval from April 2002 to April 2009.

Regression results between US and UK markets into FC time duration.

\begin{tabular}{cccccc}
\hline & Coefficient & Std.Error & t-value & t-prob & Part.R \\
\hline$a_{0}$ & -1.21608 & 0.06761 & -18.0 & 0.000 & 0.1551 \\
$a_{1}$ & 0.970320 & 0.007934 & 122.0 & 0.000 & 0.8946
\end{tabular}

RSS: (6.0672123), $\left(\mathrm{R}^{2}\right): 0.89462$

$\mathrm{F}(1,1762)=1.496 \mathrm{e}+004[0.000]^{* *}$

Log-likelihood (2500.08); DW: (0.0881)

Notes: The regression equation is $\left(U S_{t}=a_{0}+a_{1} U K_{t}+u_{t}\right) . U S_{t}$ is represented by S\&P 500 index data, and $U K_{t}$ is represented by FTSE 100 index data. Both samples of data are referred to time interval from April 2002 to April 2009.

Regression results between UK and ASIA markets into FC time duration.

\begin{tabular}{lccccc}
\hline & Coefficient & Std.Error & t-value & t-prob & Part. $R^{2}$ \\
\hline$a_{0}$ & 3.71314 & 0.06310 & 58.8 & 0.000 & 0.6648 \\
$a_{1}$ & 0.500136 & 0.006561 & 76.2 & 0.000 & 0.7689 \\
RSS: $(12.6365654),\left(\mathrm{R}^{2}\right): 0.768933$ & & & \\
F(1,1746) = 5810 [0.000]** & & & \\
\multicolumn{2}{l}{ Log-likelihood: $(1828.19)$; DW: $(0.0352)$} & & \\
\hline
\end{tabular}

Notes: The regression equation is $\left(U K_{t}=a_{0}+a_{1} H S_{t}+u_{t}\right) . U K_{t}$ is represented by FTSE 100 index data, and $H S_{t}$ is represented by Hang Seng index data. Both samples of data are referred to time interval from April 2002 to April 2009.

is the residual variance in the system measuring Granger flow from the $j^{\text {th }}$ to the $i^{\text {th }}$ country defined above.

We need to estimate the following vector of parameters:

$$
\theta_{i}=\left(\xi_{i}, a_{i}, b_{i}, \sigma_{j \rightarrow i}^{2}\right)^{\prime}, \forall i \neq j=1,2,3 .
$$

We can compute the MLE of the above parameter by directly utilizing the OLS estimators, which satisfy the following variance equation

$$
\hat{\sigma}_{j \rightarrow i}^{2}=(1 / T) \sum_{t=1}^{T}\left(y_{i, t}-\hat{\xi}_{i}-\hat{a}_{i} y_{i, t-1}-\hat{b}_{i} y_{j, t-1}\right)^{2}
$$


Table 4. Unit root-10 ${ }^{\text {th }}$ lag-test for obtained residuals by (US/UK), (US/HS) and (UK/HS) regression equations.

Unit root test for obtained residuals from US-UK regression series before FC.

\begin{tabular}{ccccccccc}
\hline D-lag & t-adf & beta Y_1 & sigma & t-DY_lag & t-prob & AIC & F-prob \\
\hline 10 & $-2.079^{*}$ & 0.98272 & 0.01386 & -1.709 & 0.0877 & -8.547 & \\
9 & $-2.230^{*}$ & 0.98151 & 0.01387 & -2.086 & 0.0372 & -8.546 & 0.0877 \\
8 & $-2.419^{*}$ & 0.97998 & 0.01389 & 2.735 & 0.0064 & -8.544 & 0.0266 \\
7 & $-2.204^{*}$ & 0.98177 & 0.01394 & -3.425 & 0.0006 & -8.538 & 0.0021 \\
6 & $-2.500^{*}$ & 0.97928 & 0.01401 & -1.033 & 0.3017 & -8.528 & 0.0000 \\
5 & $-2.603^{* *}$ & 0.97851 & 0.01402 & -4.823 & 0.0000 & -8.529 & 0.0000 \\
4 & $-3.089^{* *}$ & 0.97436 & 0.01417 & -3.144 & 0.0017 & -8.508 & 0.0000 \\
3 & $-3.456^{* *}$ & 0.97137 & 0.01423 & -4.371 & 0.0000 & -8.500 & 0.0000 \\
2 & $-4.035^{* *}$ & 0.96658 & 0.01436 & 0.7119 & 0.4767 & -8.483 & 0.0000 \\
1 & $-3.977^{* *}$ & 0.96734 & 0.01436 & 0.1157 & 0.9079 & -8.485 & 0.0000 \\
0 & $-3.998^{* *}$ & 0.96746 & 0.01435 & & & -8.487 & 0.0000 \\
\hline
\end{tabular}

Notes: The estimation period is considered to be the interval (April 2002-April 2006). The above results were based on PcGive output where the rejection criteria are obviously shown.

Unit root test for obtained residuals from US-ASIA regression series before FC.

\begin{tabular}{cccccccc}
\hline D-lag & t-adf & beta Y_1 & sigma & t-DY_lag & t-prob & AIC & F-prob \\
\hline 10 & $-3.861^{* *}$ & 0.96067 & 0.01241 & -0.6097 & 0.5422 & -8.767 & \\
9 & $-3.988^{* *}$ & 0.95979 & 0.01241 & -0.5517 & 0.5813 & -8.769 & 0.5422 \\
8 & $-4.109^{* *}$ & 0.95900 & 0.01240 & 1.287 & 0.1984 & -8.771 & 0.7133 \\
7 & $-3.969^{* *}$ & 0.96076 & 0.01241 & -1.591 & 0.1118 & -8.771 & 0.5071 \\
6 & $-4.242^{* *}$ & 0.95847 & 0.01242 & 0.5925 & 0.5536 & -8.770 & 0.3026 \\
5 & $-4.202^{* *}$ & 0.95929 & 0.01241 & -0.003504 & 0.9972 & -8.772 & 0.3912 \\
4 & $-4.248^{* *}$ & 0.95929 & 0.01241 & -0.8384 & 0.4020 & -8.774 & 0.5172 \\
3 & $-4.422^{* *}$ & 0.95809 & 0.01240 & 1.268 & 0.2053 & -8.775 & 0.5500 \\
2 & $-4.282^{* *}$ & 0.95985 & 0.01241 & 0.4072 & 0.6840 & -8.776 & 0.4823 \\
1 & $-4.269^{* *}$ & 0.96039 & 0.01240 & -0.4960 & 0.6200 & -8.778 & 0.5664 \\
0 & $-4.393^{* *}$ & 0.95971 & 0.01240 & & & -8.779 & 0.6355 \\
\hline
\end{tabular}

Notes: The estimation period is considered to be the interval (April 2002-April 2006). The above results were based on PcGive output where the rejection criteria are obviously shown.

Unit root test for obtained residuals from UK-ASIA regression series before FC.

\begin{tabular}{cccccccc}
\hline D-lag & t-adf & beta Y_1 & sigma & t-DY_lag & t-prob & AIC & F-prob \\
\hline 10 & $-2.489^{*}$ & 0.97922 & 0.01319 & -2.301 & 0.0216 & -8.646 & \\
9 & $-2.815^{* *}$ & 0.97665 & 0.01321 & 1.319 & 0.1874 & -8.643 & 0.0216 \\
8 & $-2.666^{* *}$ & 0.97807 & 0.01322 & 1.522 & 0.1284 & -8.643 & 0.0299 \\
7 & $-2.493^{*}$ & 0.97964 & 0.01323 & 2.201 & 0.0280 & -8.643 & 0.0252 \\
6 & $-2.239^{*}$ & 0.98182 & 0.01325 & -1.256 & 0.2095 & -8.640 & 0.0068 \\
5 & $-2.416^{*}$ & 0.98053 & 0.01326 & -0.8535 & 0.3936 & -8.640 & 0.0076 \\
4 & $-2.551^{*}$ & 0.97962 & 0.01326 & 1.024 & 0.3062 & -8.641 & 0.0114 \\
3 & $-2.440^{*}$ & 0.98066 & 0.01326 & -4.177 & 0.0000 & -8.642 & 0.0143 \\
2 & $-3.030^{* *}$ & 0.97603 & 0.01337 & 1.455 & 0.1461 & -8.627 & 0.0000 \\
1 & $-2.857^{* *}$ & 0.97760 & 0.01338 & -2.060 & 0.0397 & -8.627 & 0.0000 \\
0 & $-3.185^{* *}$ & 0.97525 & 0.01340 & & & -8.624 & 0.0000 \\
\hline
\end{tabular}

Notes: The estimation period is considered to be the interval (April 2002-April 2006). The above results were based on PcGive output where the rejection criteria are obviously shown. 
Unit root test for obtained residuals from US-UK regression series including FC.

\begin{tabular}{cccccccc}
\hline D-lag & t-adf & beta Y_1 & sigma & t-DY_lag & t-prob & AIC & F-prob \\
\hline 10 & $-3.005^{* *}$ & 0.97873 & 0.01646 & -1.516 & 0.1297 & -8.208 & \\
9 & $-3.123^{* *}$ & 0.97795 & 0.01646 & -1.992 & 0.0465 & -8.208 & 0.1297 \\
8 & $-3.278^{* *}$ & 0.97690 & 0.01648 & -0.8478 & 0.3967 & -8.206 & 0.0438 \\
7 & $-3.354^{* *}$ & 0.97643 & 0.01648 & -5.261 & 0.0000 & -8.207 & 0.0726 \\
6 & $-3.804^{* *}$ & 0.97317 & 0.01660 & -3.494 & 0.0005 & -8.193 & 0.0000 \\
5 & $-4.134^{* *}$ & 0.97088 & 0.01665 & -1.669 & 0.0954 & -8.187 & 0.0000 \\
4 & $-4.313^{* *}$ & 0.96975 & 0.01666 & -0.7336 & 0.4633 & -8.186 & 0.0000 \\
3 & $-4.407^{* *}$ & 0.96924 & 0.01666 & -0.8469 & 0.3972 & -8.187 & 0.0000 \\
2 & $-4.517^{* *}$ & 0.96864 & 0.01666 & -4.029 & 0.0001 & -8.188 & 0.0000 \\
1 & $-4.991^{* *}$ & 0.96542 & 0.01673 & -9.822 & 0.0000 & -8.180 & 0.0000 \\
0 & $-6.328^{* *}$ & 0.95547 & 0.01718 & & & -8.127 & 0.0000 \\
\hline
\end{tabular}

Notes: The estimation period is considered to be the interval (April 2002-April 2009). The above results were based on PcGive output where the rejection criteria are obviously shown.

Unit root test for obtained residuals from US-ASIA regression series including FC.

\begin{tabular}{ccccccccc}
\hline D-lag & t-adf & beta Y_1 & sigma & t-DY_lag & t-prob & AIC & F-prob \\
\hline 10 & $-3.372^{* *}$ & 0.98750 & 0.01492 & -0.1789 & 0.8581 & -8.403 & \\
9 & $-3.378^{* *}$ & 0.98748 & 0.01492 & 0.6637 & 0.5070 & -8.404 & 0.8581 \\
8 & $-3.365^{* *}$ & 0.98754 & 0.01492 & 0.6143 & 0.5391 & -8.405 & 0.7897 \\
7 & $-3.351^{* *}$ & 0.98759 & 0.01492 & -1.759 & 0.0788 & -8.406 & 0.8376 \\
6 & $-3.399^{* *}$ & 0.98741 & 0.01492 & -0.2129 & 0.8314 & -8.406 & 0.4147 \\
5 & $-3.407^{* *}$ & 0.98739 & 0.01492 & -2.020 & 0.0435 & -8.407 & 0.5520 \\
4 & $-3.459^{* *}$ & 0.98719 & 0.01493 & -2.055 & 0.0400 & -8.405 & 0.2343 \\
3 & $-3.527 * *$ & 0.98694 & 0.01495 & -0.7434 & 0.4573 & -8.404 & 0.0922 \\
2 & $-3.558^{* *}$ & 0.98683 & 0.01495 & -4.667 & 0.0000 & -8.405 & 0.1183 \\
1 & $-3.760^{* *}$ & 0.98602 & 0.01503 & -6.006 & 0.0000 & -8.394 & 0.0001 \\
0 & $-4.101 * *$ & 0.98463 & 0.01519 & & & -8.374 & 0.0000 \\
\hline
\end{tabular}

Notes: The estimation period is considered to be the interval (April 2002-April 2009). The above results were based on PcGive output where the rejection criteria are obviously shown.

Unit root test for obtained residuals from UK-ASIA regression series including FC.

\begin{tabular}{ccccccccc}
\hline D-lag & t-adf & beta Y_1 & sigma & t-DY_lag & t-prob & AIC & F-prob \\
\hline 10 & $-2.636^{* *}$ & 0.98807 & 0.01538 & -1.954 & 0.0508 & -8.343 & \\
9 & $-2.729^{* *}$ & 0.98766 & 0.01540 & 0.2572 & 0.7971 & -8.342 & 0.0508 \\
8 & $-2.720^{* *}$ & 0.98772 & 0.01539 & 1.151 & 0.2500 & -8.343 & 0.1436 \\
7 & $-2.666^{* *}$ & 0.98798 & 0.01539 & 0.06629 & 0.9472 & -8.343 & 0.1574 \\
6 & $-2.667^{* *}$ & 0.98799 & 0.01539 & -3.789 & 0.0002 & -8.344 & 0.2663 \\
5 & $-2.886^{* *}$ & 0.98698 & 0.01545 & -3.279 & 0.0011 & -8.337 & 0.0016 \\
4 & $-3.099^{* *}$ & 0.98600 & 0.01549 & 2.248 & 0.0247 & -8.332 & 0.0000 \\
3 & $-2.960^{* *}$ & 0.98664 & 0.01551 & -6.017 & 0.0000 & -8.330 & 0.0000 \\
2 & $-3.406^{* *}$ & 0.98452 & 0.01567 & -2.834 & 0.0046 & -8.311 & 0.0000 \\
1 & $-3.641^{* *}$ & 0.98348 & 0.01570 & -4.886 & 0.0000 & -8.307 & 0.0000 \\
0 & $-4.102^{* *}$ & 0.98135 & 0.01580 & & & -8.295 & 0.0000 \\
\hline
\end{tabular}

Notes: The estimation period is considered to be the interval (April 2002-April 2009). The above results were based on PcGive output where the rejection criteria are obviously shown. 
Based on the above, we arrive at the following loglikelihood expression for our system

$$
\log \hat{L}=(-T / 2) \log (2 \pi)-(T / 2) \log \left(\hat{\sigma}_{j \rightarrow i}^{2}\right)-T / 2
$$

We can suppose the same for the univariate system, where our data are generated by an AR(1) model. In this case the estimated variance is given by

$$
\hat{\sigma}_{i}^{2}=(1 / T) \sum_{t=1}^{T}\left(y_{i, t}-\hat{a}_{i}-\hat{p}_{i} y_{i, t-1}\right)^{2} \quad \forall i=1,2,3
$$

And the corresponding log-likelihood is given by:

$$
\log \hat{L}^{\prime}=(-T / 2) \log (2 \pi)-(T / 2) \log \left(\hat{\sigma}_{i}^{2}\right)-T / 2
$$

Based on Engle [14] the Wald and LR statistics are asymptotically equivalent and we may thus use any of two in order to test for causality.

The likelihood ratio and Wald statistics are given respectively as follows:

$$
\begin{gathered}
L R=T \log \left(\frac{\hat{\sigma}_{i}^{2}}{\hat{\sigma}_{j \rightarrow i}^{2}}\right) \\
W=\frac{\left(\hat{c}_{i j}^{2}\right)}{\operatorname{var}\left(\hat{c}_{i j}\right)}
\end{gathered}
$$

\subsubsection{Empirical Results}

Table 5 presents the results from the Granger causality test for all our series before the financial crisis (FC period) and including the financial crisis (FC) returns. The major finding is that, as we will explain, information flows and precedence of information have changed when examining data before and including the financial crisis. Specifically, using only financial data from the three markets that exclude the financial crisis period, we observe that the only two hypotheses that are acceptable (i.e., we cannot safely reject) are that the US and UK markets cannot transmit information to the Hong Kong market.

This finding is very reasonable: with 8 hours of difference in local time ${ }^{4}$ between the UK and HS (and 13 hours of difference in local time ${ }^{5}$ between the US and HS) while events that occur when the Hong Kong market is open will be captured by both HS returns as well as UK (US) returns this is not necessarily true for information released during the UK market hours. The hypothesis that:

\section{HS market does not precede the UK}

has a p-value of 0.0289 and is rejected. It will actually be impossible for information released during the US hours

${ }^{4} 7$ hours in the summer months due to Daylight saving time in the UK but not in Hong Kong.

${ }^{5} 12$ hours in the summer months due to Daylight saving time in NY (US) but not in Hong Kong.
Table 5. Results for G-cause test; Evidence of changing information flows during the Financial Crisis.

Granger causality test between US and UK market before FC period.

\begin{tabular}{cccc}
\hline Ho: US-UK & T & W-Statistic & Prob. \\
\hline US $_{\mathrm{t}}$ does not Granger Cause $\mathrm{UK}_{\mathrm{t}}$ & 1006 & 4.62929 & 0.0032 \\
UK $_{\mathrm{t}}$ does not Granger Cause US & & 5.81556 & 0.0006 \\
\hline
\end{tabular}

Granger causality test between US and ASIA market before FC period.

\begin{tabular}{cccc}
\hline Ho: US-ASIA & T & W-Statistic & Prob. \\
\hline HS $_{\mathrm{t}}$ does not Granger Cause US & 992 & 11.8204 & $1 . \mathrm{t}-07$ \\
US $_{\mathrm{t}}$ does not Granger Cause HS & & 0.69536 & 0.5550 \\
\hline
\end{tabular}

Granger causality test between UK and ASIA market before FC period.

\begin{tabular}{cccc}
\hline Ho: UK-ASIA & T & W-Statistic & Prob. \\
\hline HS $_{\mathrm{t}}$ does not Granger Cause UK & 992 & 3.02159 & 0.0289 \\
UK $_{\mathrm{t}}$ does not Granger Cause $\mathrm{HS}_{\mathrm{t}}$ & & 1.28067 & 0.2797 \\
\hline
\end{tabular}

Granger causality test between US and UK market including FC period.

\begin{tabular}{cccc}
\hline Ho: US-UK & T & W-Statistic & Prob. \\
\hline UK $_{\mathrm{t}}$ does not Granger Cause US & 1758 & 3.31212 & 0.0030 \\
US $_{\mathrm{t}}$ does not Granger Cause UK & & 15.0440 & $7 . \mathrm{t}-17$ \\
\hline
\end{tabular}

Granger causality test between US and ASIA market including FC period.

\begin{tabular}{cccc}
\hline Ho: US-ASIA & T & W-Statistic & Prob. \\
\hline HS $_{\mathrm{t}}$ does not Granger Cause US & 1743 & 22.8007 & $3 . \mathrm{E}-22$ \\
US $_{\mathrm{t}}$ does not Granger Cause HS & & 4.91486 & 0.0002 \\
\hline
\end{tabular}

Granger causality test between UK and ASIA market including FC period.

\begin{tabular}{cccc}
\hline Ho: UK-ASIA & T & W-Statistic & Prob. \\
\hline HS $_{\mathrm{t}}$ does not Granger Cause UK & 1743 & 23.0404 & $2 . \mathrm{E}-22$ \\
UK $_{\mathrm{t}}$ does not Granger Cause $\mathrm{HS}_{\mathrm{t}}$ & & 1.70614 & 0.1299 \\
\hline
\end{tabular}

of operation to get incorporated in same day returns for the HS and this is why the hypothesis that

\section{HS market does not precede the US}

has a p-value of only $1 \times 10^{-7}$ and is thus strongly rejected.

While it was very difficult for information to flow from the US to Asia before the crisis (p-value of 0.5550) it becomes clear that information does flow from the US to HS when we include the FC period (p-value of 0.0002).

This evidence of a newly produced channel of information from the US to Asia is quite an amazing finding and, to our knowledge, the first statistical verification 
that the 2008 crisis was truly "made in the US." The dramatic opening of this new channel of information flow from the US to Asia is registered in the precipitous drop of the p-value (2775 times lower than the p-value that excludes the crisis). This drop is a clear indication that during the financial crisis period the ability of the US markets to produce, capture and disseminate crisis specific information was unmatched by the financial markets in other regions of the world.

At the same time, due to the operating hours' overlap between the US and the UK, we reject the null that $U S_{t}$ does not instantaneously G-cause $U K_{t}$ in both examining periods and we conclude that there is a simultaneous interaction between the two markets. Moreover, the Asian market affects UK market but the opposite is not true. We are going to accept (cannot reject) the null of no G-causality from UK to Asia. This means that while it seems Asia affects UK, at the same time it is not affected by UK. This result remains significant during the FC horizon. Before FC, the Asian market did G-cause the US market but the opposite flow did not exist in the sense that the US market did not G-cause Asian markets. When we include the FC period in the analysis, we find an instantaneous interaction between the two markets, which means that we strongly reject the null of no Granger cause effect.

\section{Volatility Link between the Markets}

In this section, we finally proceed in analyzing the 2008 financial crisis and how it is manifested by changes in the volatility dynamics of the three markets. We have already observed that the markets are co-integrated, which means that price movements of one market index are strongly related to movements of the other market indices. This interrelated nature of financial markets is a key factor in contemporary financial analysis, and it is often statistically modelled as a multivariate GARCH time series model. Such models contain multiple return series of the co-integrated markets, and their main purpose is to facilitate the analysis of the variance and covariance dynamics among the multiple return series.

We use continuously compounded returns of the three main market indices under study: the US index-S\&P 500, the UK index-FTSE 100 and the Hang Seng index for ASIA. We apply the leading multivariate GARCH specification, the Diagonal VECH ${ }^{6}$ model [15] in order to capture multivariate volatility dynamics. We model the returns as a summation of a constant and an innovation of the series:

$$
\boldsymbol{r}_{t}=\boldsymbol{\mu}+\boldsymbol{u}_{t}
$$

where $\boldsymbol{r}_{t}=\left(r_{F T S E, t}, r_{H S, t}, r_{S P, t}\right)^{\prime}, \boldsymbol{\mu}=\left(\mu_{F T S E}, \mu_{H S}, \mu_{S P}\right)^{\prime}, \boldsymbol{u}_{t}=$ $\left(u_{F T S E, t}, u_{H S, t}, u_{S P, t}\right)^{\prime}$.
The conditional covariance matrix of the innovation vector $\boldsymbol{u}_{t}$, given the information set $\mathfrak{J}_{t-1}$, is defined as $\boldsymbol{H}_{t}=\boldsymbol{C o v}\left(\boldsymbol{u}_{t} \mid \mathfrak{I}_{t-1}\right)$. The $(p, q)$-lag DVECH for volatility modeling assumes a time varying $\boldsymbol{H}_{t}$ that follows dynamics defined by,

$$
\boldsymbol{H}_{t}=\boldsymbol{C}+\sum_{i=1}^{p} \boldsymbol{A}_{i} \circ\left(\boldsymbol{u}_{t-i} \boldsymbol{u}_{t-i}^{\prime}\right)+\sum_{j=1}^{q} \boldsymbol{B}_{j} \circ \boldsymbol{H}_{t-j}
$$

We employ an DVECH $(1,1)$ model in order to analyze our series. Then we take the following form of (19):

$$
\boldsymbol{H}_{t}=\boldsymbol{C}+\boldsymbol{A} \circ\left(\boldsymbol{u}_{t-1} \boldsymbol{u}_{t-1}^{\prime}\right)+\boldsymbol{B} \circ \boldsymbol{H}_{t-1}
$$

where

$$
\boldsymbol{H}_{t}=\left[\begin{array}{ccc}
h_{11, t} & \cdot & \cdot \\
h_{21, t} & h_{22, t} & \cdot \\
h_{31, t} & h_{32, t} & h_{33, t}
\end{array}\right],
$$

is the covariance matrix and its diagonal elements constitute the variance components of (FTSE, $H S, S P$ ) while the cross products are the covariance elements between the series. The element $\left(h_{21, t}\right)$ expresses the time varying correlation between (HS, FTSE), $\left(h_{31, t}\right)$ expresses the time varying correlation between $(S P, F T S E)$ and the element $\left(h_{32, t}\right)$ expresses the time varying correlation between $(S P, H S)$.

The matrix $(\boldsymbol{C})$ contains the constant terms and matrices $(\boldsymbol{A}, \boldsymbol{B})$ contain the ARCH and GARCH coefficients respectively ${ }^{7}$.

We analyze up to seven years of daily data in order to capture the dynamic volatility process of the multiple return series before and during the $\mathrm{FC}$ period. The results are as follow:

Figures 1 and $\mathbf{2}$ show the time plot of returns for each series before and including the FC period while Figures $\mathbf{3}$ and $\mathbf{4}$ show the estimated volatilities for continuously compounded returns for each index market. Moreover, Figures 3 and $\mathbf{4}$ present the time-varying covariance of DVEC $(1,1)$ model for continuously compounded returns of the three index markets.

Furthermore, we saw only the conditional variance and covariance with the above modelling procedure, but we have not yet a clear view about the correlation between the markets and if they are affected by the changing direction of information flows as we described in the previous section. It is necessary to test the conditional covariance for significance, with a formal structure of the correlation coefficient.

This test can be done by using the Constant Correlation Coefficient (CCC) model [17] that is based on the following specification structure for conditional covariance:

${ }^{6}$ The Diagonal VECH model essentially writes the covariance matrix as a set of univariate GARCH models.

${ }^{7}$ For more details see [16]. 
Table 6. Estimated coefficients for mean return equation and DVEC $(1,1)$ before and during FC.

Before FC

\begin{tabular}{|c|c|c|c|c|}
\hline Mean return coefficient vector: $(\boldsymbol{\mu})$ & Coefficient & Std. Error & z-Statistic & Prob. \\
\hline$\mu_{\mathrm{ftse}}$ & 0.000511 & 0.000230 & 2.224485 & 0.0261 \\
\hline$\mu_{\mathrm{hs}}$ & 0.000599 & 0.000290 & 2.067863 & 0.0387 \\
\hline$\mu_{\mathrm{SP}}$ & 0.000426 & 0.000247 & 1.726561 & 0.0842 \\
\hline Variance Equation: & \multicolumn{3}{|c|}{$\boldsymbol{H}_{t}=\boldsymbol{C}+\boldsymbol{A} \circ\left(\boldsymbol{u}_{t-1} \boldsymbol{u}_{t-1}^{\prime}\right)+\boldsymbol{B} \circ \boldsymbol{H}_{t-1}$} & \\
\hline $\mathrm{C}_{11}$ & $9.97 \mathrm{E}-07$ & 4.07E-07 & 2.448850 & 0.0143 \\
\hline $\mathrm{C}_{21}$ & $-3.48 \mathrm{E}-08$ & 4.65E-07 & -0.074856 & 0.9403 \\
\hline $\mathrm{C}_{31}$ & $1.94 \mathrm{E}-07$ & $1.38 \mathrm{E}-07$ & 1.404257 & 0.1602 \\
\hline $\mathrm{C}_{22}$ & 4.62E-07 & $2.87 \mathrm{E}-07$ & 1.606839 & 0.1081 \\
\hline $\mathrm{C}_{32}$ & $-2.04 \mathrm{E}-09$ & $3.74 \mathrm{E}-08$ & -0.054479 & 0.9566 \\
\hline $\mathrm{C}_{33}$ & $4.56 \mathrm{E}-07$ & $2.65 \mathrm{E}-07$ & 1.721715 & 0.0851 \\
\hline$a_{11}$ & 0.088349 & 0.016382 & 5.392995 & 0.0000 \\
\hline $\mathrm{a}_{21}$ & 0.044065 & 0.023648 & 1.863390 & 0.0624 \\
\hline$a_{31}$ & 0.023749 & 0.010437 & 2.275435 & 0.0229 \\
\hline $\mathrm{a}_{22}$ & 0.022218 & 0.007026 & 3.162415 & 0.0016 \\
\hline$a_{32}$ & 0.005319 & 0.005980 & 0.889480 & 0.3737 \\
\hline$a_{33}$ & 0.039477 & 0.009460 & 4.173234 & 0.0000 \\
\hline$b_{11}$ & 0.899975 & 0.017620 & 51.07800 & 0.0000 \\
\hline $\mathrm{b}_{21}$ & 0.791999 & 0.155694 & 5.086891 & 0.0000 \\
\hline$b_{31}$ & 0.938082 & 0.018461 & 50.81435 & 0.0000 \\
\hline$b_{22}$ & 0.972019 & 0.008729 & 111.3515 & 0.0000 \\
\hline$b_{32}$ & 0.982927 & 0.015384 & 63.89226 & 0.0000 \\
\hline$b_{33}$ & 0.952680 & 0.010816 & 88.08084 & 0.0000 \\
\hline \multicolumn{5}{|c|}{ During FC } \\
\hline Mean return coefficient vector: $(\boldsymbol{\mu})$ & Coefficient & Std. Error & z-Statistic & Prob. \\
\hline$\mu_{\mathrm{ftse}}$ & 0.000447 & 0.000191 & 2.340664 & 0.0192 \\
\hline$\mu_{\mathrm{hs}}$ & 0.000640 & 0.000247 & 2.592147 & 0.0095 \\
\hline$\mu_{\mathrm{SP}}$ & 0.000358 & 0.000202 & 1.770420 & 0.0767 \\
\hline Variance Equation: & \multicolumn{3}{|c|}{$\boldsymbol{H}_{t}=\boldsymbol{C}+\boldsymbol{A} \circ\left(\boldsymbol{u}_{t-1} \boldsymbol{u}_{t-1}^{\prime}\right)+\boldsymbol{B} \circ \boldsymbol{H}_{t-1}$} & \\
\hline $\mathrm{C}_{11}$ & $1.06 \mathrm{E}-06$ & $3.22 \mathrm{E}-07$ & 3.285715 & 0.0010 \\
\hline $\mathrm{C}_{21}$ & 7.50E-08 & $3.11 \mathrm{E}-07$ & 0.241158 & 0.8094 \\
\hline $\mathrm{C}_{31}$ & 1.19E-08 & 7.92E-08 & 0.150348 & 0.8805 \\
\hline $\mathrm{C}_{22}$ & $1.26 \mathrm{E}-06$ & $4.28 \mathrm{E}-07$ & 2.938565 & 0.0033 \\
\hline $\mathrm{C}_{32}$ & $2.82 \mathrm{E}-10$ & $1.09 \mathrm{E}-08$ & 0.026007 & 0.9793 \\
\hline $\mathrm{C}_{33}$ & $8.81 \mathrm{E}-07$ & $1.94 \mathrm{E}-07$ & 4.545649 & 0.0000 \\
\hline $\mathrm{a}_{11}$ & 0.112285 & 0.012698 & 8.842880 & 0.0000 \\
\hline$a_{21}$ & 0.021839 & 0.017917 & 1.218908 & 0.2229 \\
\hline$a_{31}$ & 0.020057 & 0.007776 & 2.579352 & 0.0099 \\
\hline$a_{22}$ & 0.069864 & 0.008514 & 8.206061 & 0.0000 \\
\hline$a_{32}$ & -0.002786 & 0.001660 & -1.678200 & 0.0933 \\
\hline $\mathrm{a}_{33}$ & 0.069628 & 0.009046 & 7.697431 & 0.0000 \\
\hline $\mathrm{b}_{11}$ & 0.886017 & 0.011934 & 74.24564 & 0.0000 \\
\hline$b_{21}$ & 0.861168 & 0.150164 & 5.734836 & 0.0000 \\
\hline$b_{31}$ & 0.952118 & 0.011549 & 82.44429 & 0.0000 \\
\hline$b_{22}$ & 0.925442 & 0.009252 & 100.0242 & 0.0000 \\
\hline $\mathrm{b}_{32}$ & 1.004232 & 0.007243 & 138.6420 & 0.0000 \\
\hline $\mathrm{b}_{33}$ & 0.924571 & 0.009607 & 96.23563 & 0.0000 \\
\hline
\end{tabular}


RETURNS FTSE 100

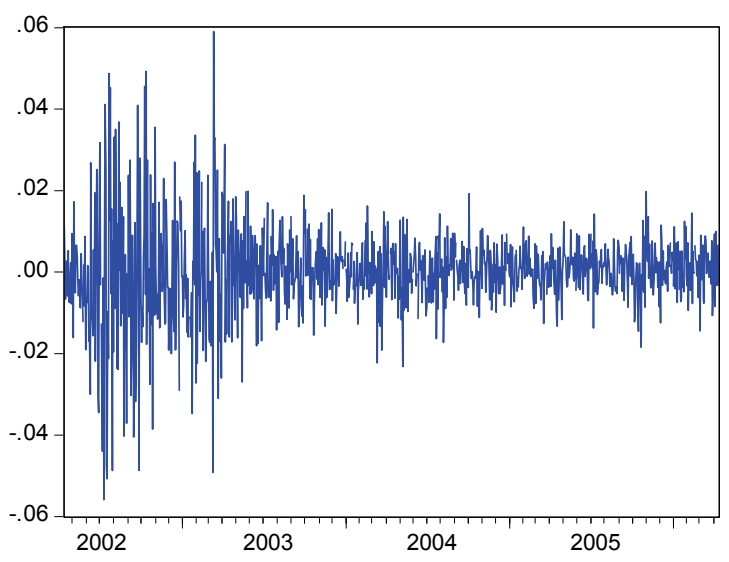

RETURNS_HS

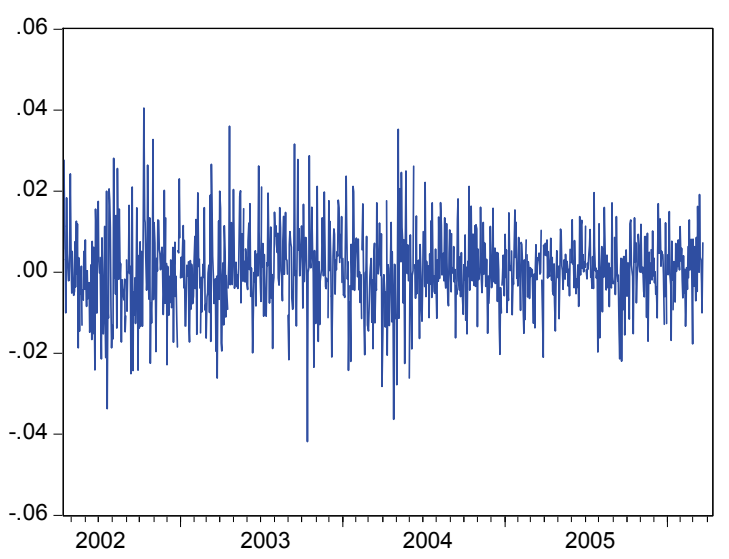

RETURNS_S\&P 500

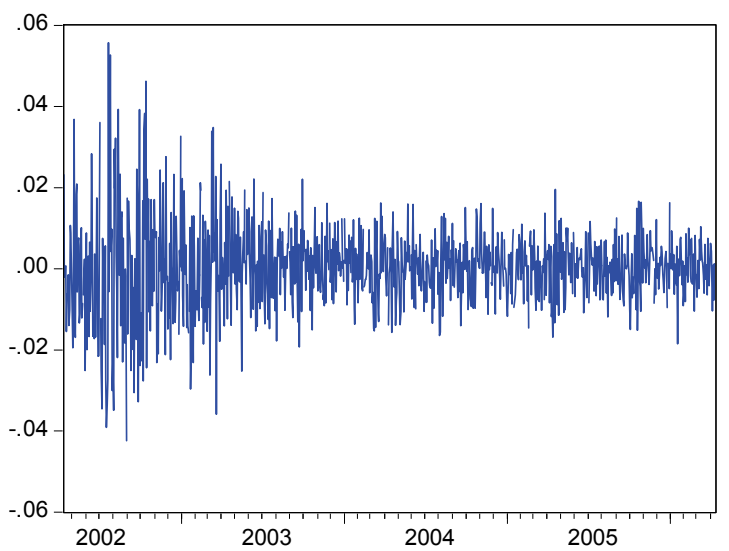

Figure 1. Continuously compounded returns of FTSE 100, S\&P 500 and Hang Seng time series before FC period.
RETURNS_FTSE 100

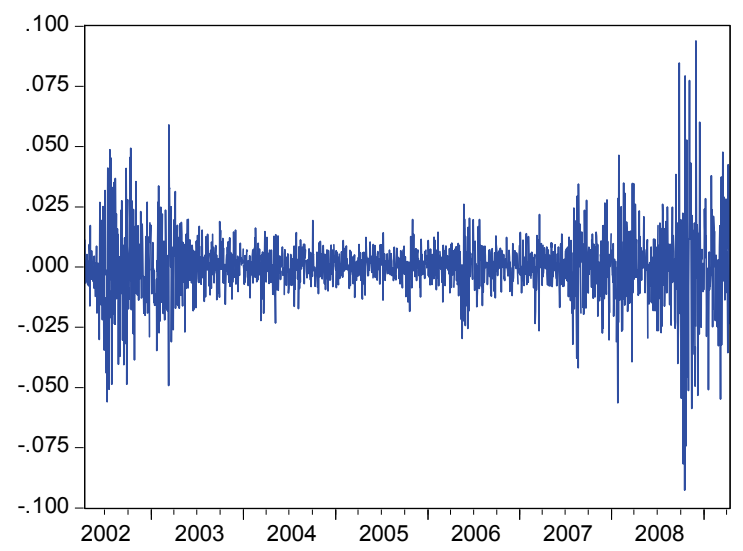

RETURNS_HS

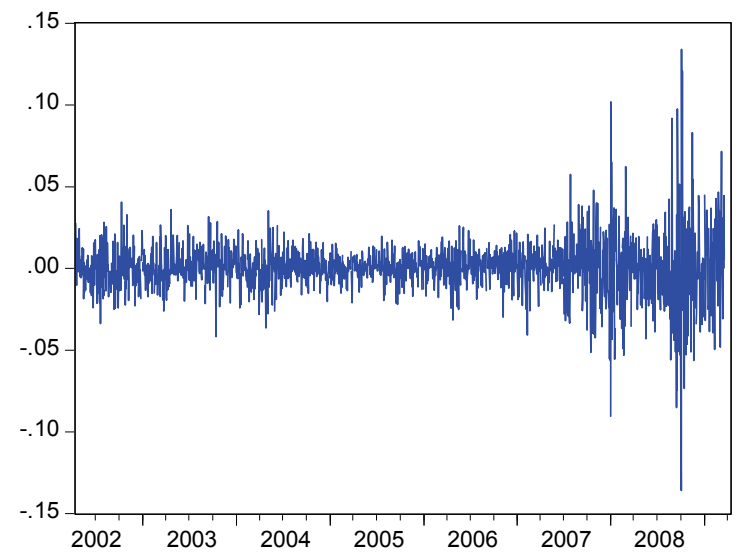

RETURNS S\&P 500

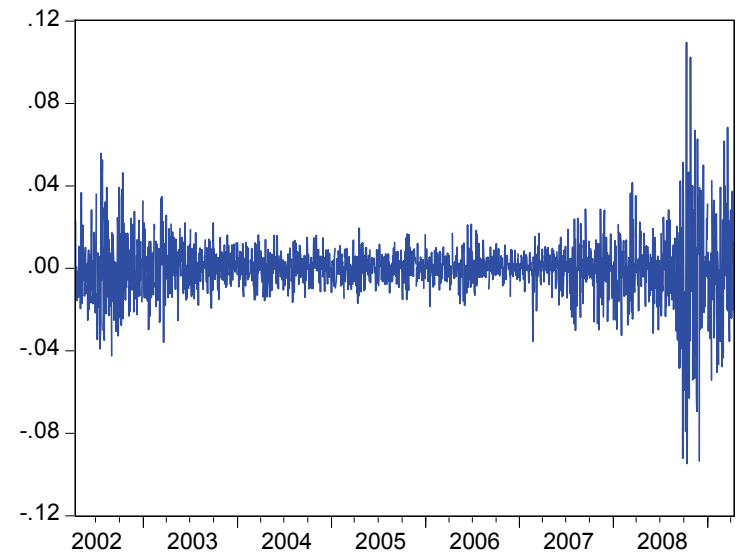

Figure 2. Continuously compounded returns of FTSE 100, S\&P 500 and Hang Seng time series during FC period. 

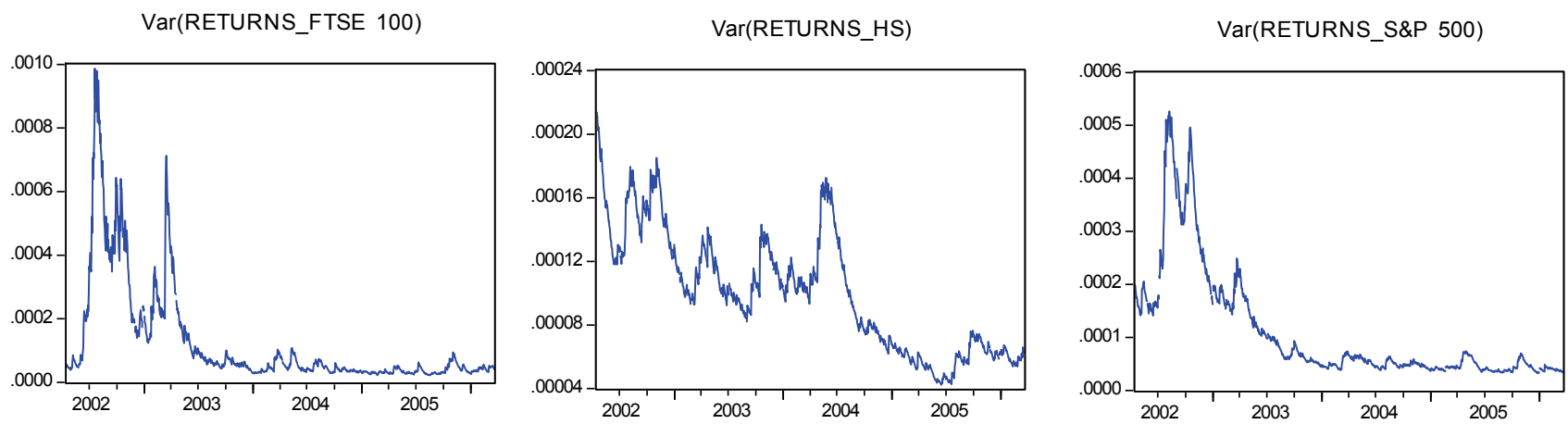

Cov(RETURNS_FTSE 100, RETURNS_HS)

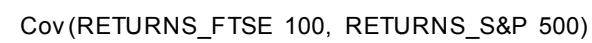

Cov(RETURNS_HS, RETURNS_S\&P 500)
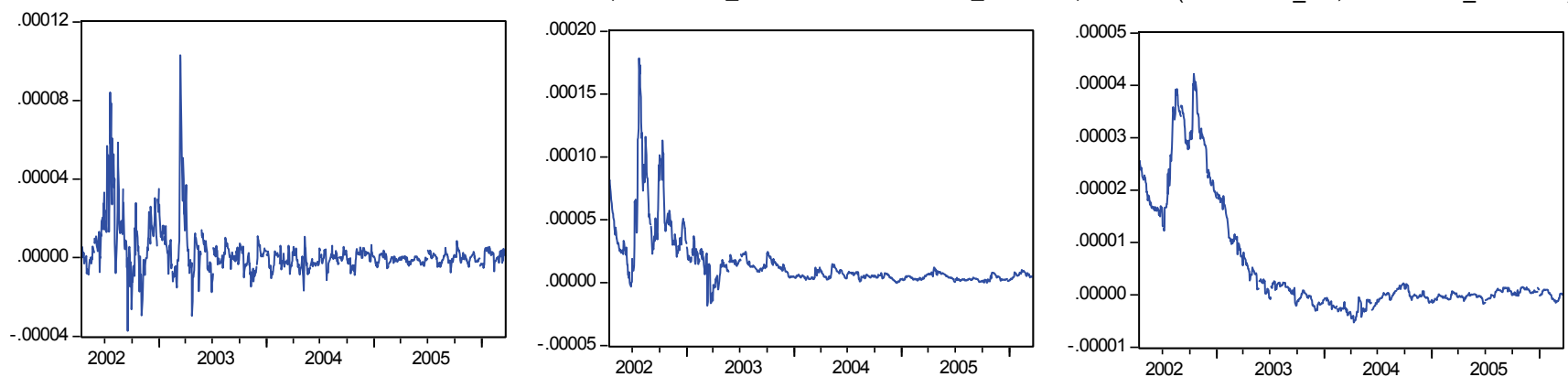

Figure 3. Conditional variance-covariance representation of estimated return series before FC time period.

Var(RETURNS FTSE 100)

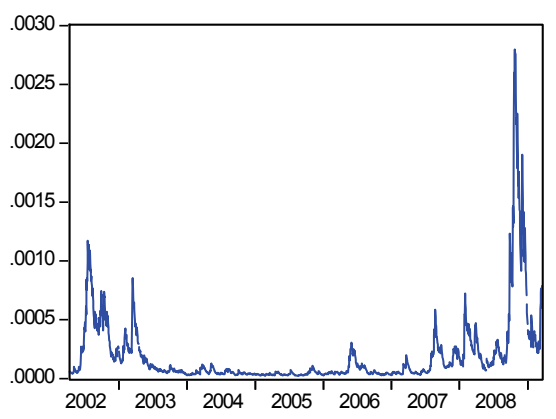

Cov(RETURNS_FTSE 100, RETURNS_HS)

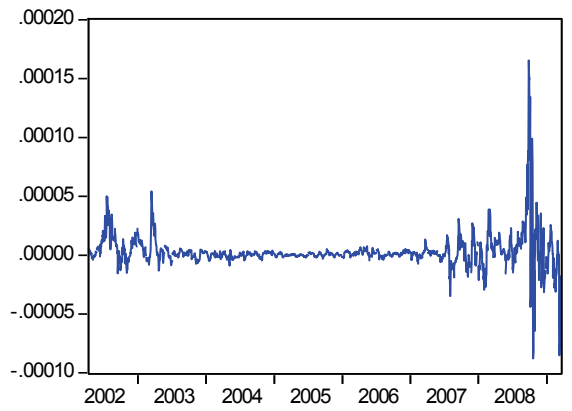

Var(RETURNS HS)

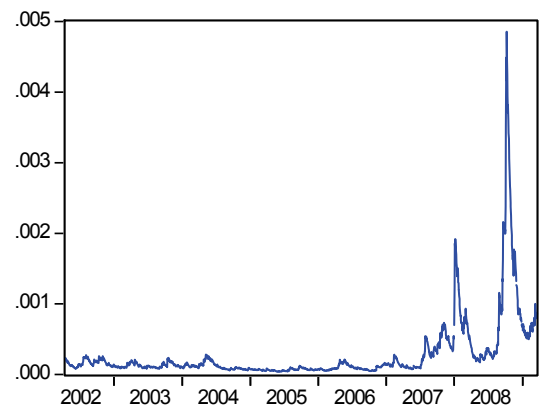

Var(RETURNS_S\&P 500)

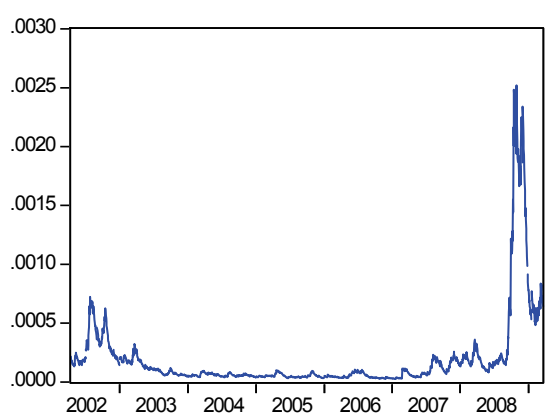

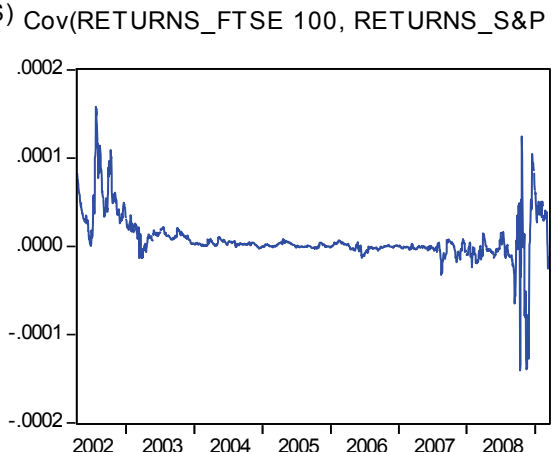

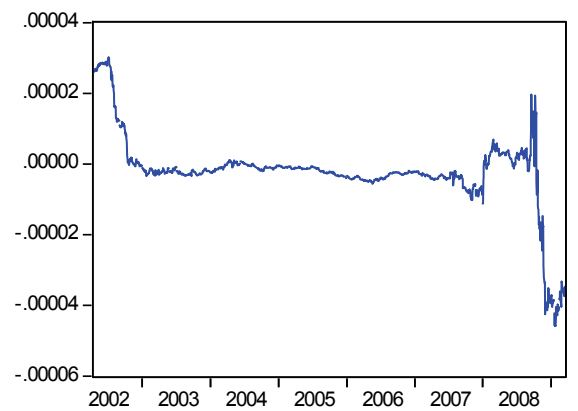

Figure 4. Conditional variance-covariance representation of estimated return series during FC time period. 


$$
h_{i j, t}=R_{i j} \sqrt{h_{i i, t} h_{j j, t}}, \forall i, j=F T S E, H S, S P
$$

The coefficient $\left(R_{i j}\right)$ is the constant correlation between the $i^{\text {th }}$ and $j^{\text {th }}$ markets while the individual market specific conditional variance following a one-dimensional GARCH

$$
h_{k k, t}=c_{k}+a_{k} u_{t-1}^{2}+b_{k} h_{k k, t-1}, \forall k
$$

Table 7. CCC estimation before and during the FC.

\begin{tabular}{ccccc}
\multicolumn{5}{c}{ Before FC } \\
\cline { 1 - 4 } CCC equation: $h_{k k, t}=c_{k}+a_{k} u_{t-1}^{2}+b_{k} h_{k k, t-1}$ \\
\multicolumn{5}{c}{$h_{i j, t}=R_{i j} \sqrt{h_{i, t} h_{j j, t}}$} \\
\hline $\mathrm{C}_{1}$ & $9.15 \mathrm{E}-07$ & $3.81 \mathrm{E}-07$ & 2.401591 & 0.0163 \\
$\mathrm{~A}_{1}$ & 0.084501 & 0.015989 & 5.284869 & 0.0000 \\
$\mathrm{~B}_{1}$ & 0.904494 & 0.017197 & 52.59597 & 0.0000 \\
$\mathrm{C}_{2}$ & $3.97 \mathrm{E}-07$ & $2.58 \mathrm{E}-07$ & 1.536159 & 0.1245 \\
$\mathrm{~A}_{2}$ & 0.021141 & 0.006642 & 3.183029 & 0.0015 \\
$\mathrm{~B}_{2}$ & 0.973830 & 0.008051 & 120.9617 & 0.0000 \\
$\mathrm{C}_{3}$ & $5.00 \mathrm{E}-07$ & $2.84 \mathrm{E}-07$ & 1.760204 & 0.0784 \\
$\mathrm{~A}_{3}$ & 0.042969 & 0.010376 & 4.141257 & 0.0000 \\
$\mathrm{~B}_{3}$ & 0.948922 & 0.011763 & 80.67114 & 0.0000 \\
$\mathrm{R}_{12}$ & 0.043517 & 0.034412 & 1.264591 & 0.2060 \\
$\mathrm{R}_{13}$ & 0.179320 & 0.029016 & 6.180103 & 0.0000 \\
$\mathrm{R}_{23}$ & 0.051741 & 0.030215 & 1.712445 & 0.0868 \\
\hline
\end{tabular}

During FC

\begin{tabular}{ccccc}
\hline \multicolumn{5}{c}{ CCC equation: $h_{k, t}=c_{k}+a_{k} u_{t-1}^{2}+b_{k} h_{k k, t-1}$} \\
\multicolumn{5}{c}{$h_{i j, t}=R_{i j} \sqrt{h_{i, t} h_{i j, t}}$} \\
\hline $\mathrm{C}_{1}$ & $9.51 \mathrm{E}-07$ & $3.06 \mathrm{E}-07$ & 3.113997 & 0.0018 \\
$\mathrm{~A}_{1}$ & 0.108262 & 0.012235 & 8.848573 & 0.0000 \\
$\mathrm{~B}_{1}$ & 0.890359 & 0.011527 & 77.23797 & 0.0000 \\
$\mathrm{C}_{2}$ & $1.29 \mathrm{E}-06$ & $4.34 \mathrm{E}-07$ & 2.965774 & 0.0030 \\
$\mathrm{~A}_{2}$ & 0.070639 & 0.008491 & 8.319351 & 0.0000 \\
$\mathrm{~B}_{2}$ & 0.924898 & 0.009231 & 100.1949 & 0.0000 \\
$\mathrm{C}_{3}$ & $8.68 \mathrm{E}-07$ & $1.92 \mathrm{E}-07$ & 4.511079 & 0.0000 \\
$\mathrm{~A}_{3}$ & 0.068459 & 0.008955 & 7.644883 & 0.0000 \\
$\mathrm{~B}_{3}$ & 0.925928 & 0.009565 & 96.80827 & 0.0000 \\
$\mathrm{R}_{12}$ & 0.044193 & 0.024588 & 1.797361 & 0.0723 \\
$\mathrm{R}_{13}$ & 0.054208 & 0.023218 & 2.334745 & 0.0196 \\
$\mathrm{R}_{23}$ & 0.007679 & 0.023962 & 0.320458 & 0.7486 \\
\hline
\end{tabular}

If we combine the above finding with the G-cause findings, we conclude that the UK and Asian markets were insignificantly positive correlated $\left(\mathrm{R}_{12}\right)$ before and remained so during the Financial Crisis. On the other hand, we cannot observe any insignificant difference in the correlation (significant correlation coefficient) between the US and UK $\left(\mathrm{R}_{13}\right)$ markets while the conditional correlation between the US and the Asian market $\left(R_{23}\right)$ remains strongly insignificant before and during the FC period. Thus it seems that information is transmitted in part through market returns and partly also through volatility spillovers in the case of US/UK.

\section{Conclusions}

An empirical objective of this paper was to examine the existence and source of the strong inter-market co-movements that are suggested by financial analysts during the 2008 financial crisis. We analyzed levels and stock returns for three indices (FTSE100, Hang Seng and S\&P500) that represent three major financial markets that constitute a major fraction of the world capitalization. We believe that these three stock markets are representative of the European, Asian and US markets respectively.

After finding that all three indices have unit roots and they are cointegrated, we performed a host of Granger causality tests in order to see the direction of information flows between the markets before and during the financial crisis. The most surprising finding is that while it was very difficult for information to flow from the US to Asia before the crisis, information did flow from the US to Asia when the crisis period is included in the sample. This provides the first evidence of a newly produced channel of information and, to our knowledge, is the first statistical verification that the 2008 crisis was truly "made in the US".

Moreover, we did not find any significant correlation coefficient, as it was modelled by a CCC model, between US/ASIA and UK/ASIA markets except among the US and UK.

\section{References}

[1] K. J. Forbes and R. Rigobon, "Contagion in Latin America: Definitions, Measurement, and Policy Implications," Economia, Vol. 1, No. 2, 2001, pp. 1-46.

[2] A. Lo and A. C. Mackinlay, "An Econometric Analysis of Nonsynchronous Trading," Journal of Econometrics, Vol. 45, No. 1-2, 1990, pp. 181-211.

[3] R. Engle, "Autoregressive Conditional Heteroskedasticity with Estimates of theVariance of U.K. Inflation," Econometrica, Vol. 50, No. 4, 1982, pp. 987-1008.

[4] R. Engle, "Arch Selected Readings," Oxford University 
Press, Oxford, 1995.

[5] R. Engle, "The use of ARCH/GARCH Models in Applied Econometrics," Journal of Economic Perspectives, Vol. 15, No. 4, 2001, pp. 157-168.

[6] T. Bollerslev, "Generalized Autoregressive Conditional Heteroscedasticity," Journal of Econometrics, Vol. 31, No. 3, 1986, pp. 307-327.

[7] T. Bollerslev, R. F. Engle and D. B. Nelson, "ARCH Models," In: R. Engle and D. McFadden, Eds., Handbook of Econometrics, North Holland Press, Amsterdam, 1994.

[8] D. A. Dickey and W. A. Fuller, "Distributions of the Estimators for Autoregressive Time Series with a Unit Root," Journal of American Statistical Association, Vol. 74, No. 366, 1979, pp. 427-481.

[9] D. A. Dickey and W. A. Fuller, "Likelihood Ratio Statistics for Autoregressive Time Series with a Unit Root," Econometrica, Vol. 49, No. 4, 1981, pp. 1057-1072.

[10] H. Akaike, "Information Theory and an Extension of the Maximum Likelihood Principle," In: B. N. Petrov and Csaki, Eds., 2nd International Symposium on Information Theory, Academia Kiado, Budapest, 1973, pp. 267-281.
[11] R. Harris and R. Sollis, "Applied Time Series Modelling and Forecasting," John Wiley, New York, 2003.

[12] R. F. Engle and C. W. J. Granger, "Cointegration and Error Correction: Representation, Estimation and Testing," Econometrica, Vol. 55, No. 2, 1987, pp. 251-276.

[13] C. Gourieroux and J. Jasiak, "Financial Econometrics," Princeton University Press, Princeton and Oxford, 2001.

[14] R. Engle, "Wald, Likelihood Ratio and Lagrange Multiplier Tests in Econometrics," In: Z. Griliches and M. D. Intriligator, Eds., Handbook of Econometrics II, 1983, pp. 796-801.

[15] T. Bollerslev, R. Engle and J. M. Wooldridge, "A Capital-Asset Pricing Model with Time-Varying Covariances," Journal of political Economy, Vol. 96, No. 1, 1988, pp. 116-131.

[16] R. Tsay, "Analysis of Financial Time Series," John Wiley \& Sons, New Jersey, 2005.

[17] T. Bollerslev, "Modeling the Coherence in Short-Term Nominal Exchange Rates: A Multivariate Generalized ARCH Approach," Review of Economics and Statistics, 1990. 